CRES Technical Report 177-35

Fawwaz T. Ulaby

April 1973

Supported by:

NATIONAL AERONAUTICS AND SPACE ADMINISTRATION Johnson Spacecraft Center Houston, Texos 77058

CONTRACT NAS 9-10261

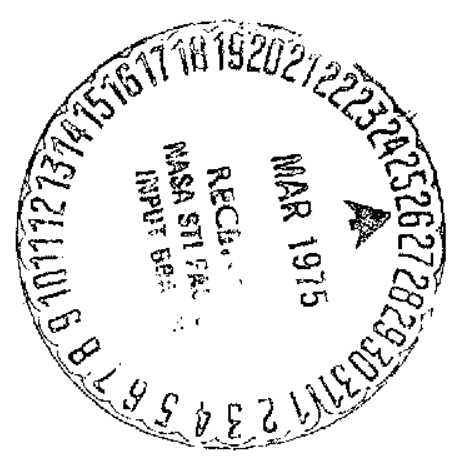




\section{ACKNOWLEDGMENTS}

This research was conducted under the sponsorship of the National Aeronautics and Space Administration, Contract NAS 9-10261, and the U. S. Army Engineer Topographic Laboratories Project THEMIS Contract DAAK02-68-C-0089. Dr. R. K. Moore is the principal investigator of both contracts.

The outhor would like to express his gratitude to Professor R. K. Moore, Director of the Remote Sensing Laboratory at the University of Kansas, Lawrence, for proposing this study and for his helpful advice and suidance, and to the following members of the Microwave Active and Passive Spectrometer group for their assistance in constructing the system and collecting and processing the data: Professor J. Holtzman, Mr. P. Batlivala, Mr. T. Bush, Mr. J. Cihlar, Mr. H. Khamsi, Mr. L. Ort, and Mr. J, Zeigler. 


\title{
RADAR MEASUREMENT OF SOIL MOISTURE CONTENT
}

\author{
Fawwaz T. Ulaby \\ University of Kansas Center for Research, Inc . \\ Lawrence, Kansas 66044
}

\begin{abstract}
The effect of soil moisture on the radar backscattering coefficient was investigated by measuring the 4-8 GHz spectral response from two types of baresoil fields: slightly rough and very rough, in terms of the wavelength. An FM-CW radar system mounted atop a 75-foot truck-mounted boom was used to measure the return at 10 frequency points across the $4-8 \mathrm{GHz}$ band, at 8 different look angles $\left(0^{\circ}\right.$ through $\left.70^{\circ}\right)$, and for all polarization combinations. A rotal of 17 sets of data were collected covering the range $4-36 \%$ soil moisture content by weight. The results indicate that the radar response to soil moisture content is highly dependent on the surface roughness, microwave frequency, and look angle. The response seems to be linear, however, over the range $15 \%-30 \%$ moisture content for all angles, frequencies, polarizations and surface conditions.
\end{abstract}


TABLE OF CONTENTS

Page

ACKNOWLEDGMENTS

ABSTRACT . . . . . . . . . . . . . . . . . ii

I. INTRODUCTION . . . . . . . . . . . . . . . 1

2. ObSERVATIONS . . . . . . . . . . . . . . 2

2.1 Radar System Description . . . . . . . . . . . . . . . . . 52

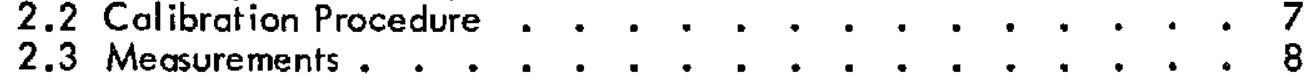

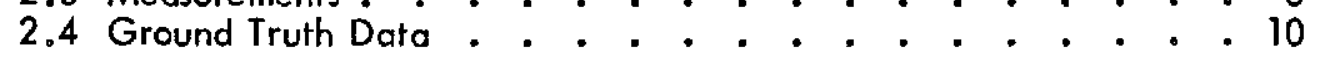

3. ANALYSIS OF THE RESULTS . . . . . . . . . . . . . . 11

3.1 Precision of Measurement . . . . . . . . . . . 11

3.2 Frequency Response . . . . . . . . . . . . . . . 13

3.3 Look Angle Response . . . . . . . . . . . . . . . 16

3.3.1 Slightly Rough Field . . . . . . . . . . 16

3.3 .2 Very Rough Field . . . . . . . . . . . . 16

3.4 Moisture Content Response . . . . . . . . . . . 18

3.4.1 Slightly Rough Field : . . . . . . : . . 18

3.4 .2 Very Rough Field . . . . . . . . . . . 20

4. PRELIMINARY DESIGN CRITERIA . . . . . . . . . . . . 24

5. CONCLUDING REMARKS . . . . . . . . . . . . . 24

REFERENCES . . . . . . . . . . . . . . . 27 


\section{INTRODUCTION}

Remote sensing of soil moisture is of primary concern to the hydrologist involved in the large-scale water resource management of farming regions [1]. Such information is also needed for flood forecasting [2] and trafficability purposes and for the location of engineering construction materials [3]. Several investigators have examined the capabilities of remote sensors operating in the optical and thermal infrared region in mapping soil moisture content $[4-7]$. Though some of the results indicate that the moisture content of bare soil does affect the surface response, microwave sensors have two potential advantages over optical and infrared sensors: 1) at the lower microwave frequencies, microwave sensors are not hampered by clouds, and 2) the skin depth of microwave frequencies will enable us to gather information about the near sub-surface as well as the surface moisture conditions, whereas at optical and infrared frequencies the sensor response contains information about a very thin layer at the air-soil interface.

Experimental work has been performed using passive microwave radiometers for the determination of soil moisture content, both under laboratory and natural conditions [ $8-10]$. The resolution of passive microwave radiometers, however, is beamwidth limited, thereby making their potential use in soil moisture discrimination from satellite altitudes limited to gross spatial differences. At aircraft altitudes, the finer possible resolution is restricted to relat ively narrow swaths. Radar, on the other hand, is capable of producing fine resolution imagery from any altitude (the theoretical resolution of a fully-focussed synthetic aperture radar is independent of range).

The effects of soil moisture on the radar return have been examined in the laboratory [11] and through the interpretation of airborne scatterometer data [12] and uncal ibrated side-looking airborne radar imagery [13] supported by limited qual itative estimates of ground truth information on soil moisture content. The in-between phase, namely that of measuring the radar return under natural conditions and with quantitative soil moisture and configuration information, was lacking. The purpose of this paper is to present some recent results on the dependency of the radar backscattering coefficient on soil moisture and surface geometry as a function of the various sensor parameters. 
Radar return from terrain is governed by two sets of parameters: 1) the radar parameters: frequency, look angle and polarization, and 2) the terrain parameters: complex dielectric properties and surface and sub-surface geometry. For terrain surfaces such as soil, the dielectric properties are strongly dependent upon the free water content in the soil; it has been shown by Lundien [11] that the effects of soil type on the value of the dielectric constant are greatly overshadowed by the effects of the free water content in the soil, particularly at the lower microwave frequencies.

The reradiation pattern from an illuminated surface is governed by the surface scale of roughness (and sub-surface if penetration and volume scattering are involved) relative to the signal wavelength. Increasing the dielectric constant of the rarget can cause a change in both the shape and the relative magnitude of the reradiation pattern due to changes in the magnitudes and phases of the reflected signals from the differential facets in the illuminated cell. Thus, the radar backscaiter exhibits a complex dependence on the surface geometry and dielectric properties. Only after extensive experimental data gathered under natural conditions and supported by the necessary ground truth information is available, will we be able to predict, with enough confidence, the characteristic behavior of the radar response from natural surfaces. The experimental results presented in this paper represent the first step in a series of long needed experiments.

\section{OBSERVATIONS}

\subsection{Radar System Description}

The radar system used in this investigation is the radar section of the University of Kansas 4-8 GHz MAPS (Microwave Active and Passive Spectrometer) system [14]; a simplified block diagram is shown in Figure 1. The radar utilizes two parabolic dish antennas mounted parallel on the same platform, which in turn is mounted onto an antenna positioner. The two antennas have been aligned (both mechanically and electromagnetically) on an antenna range, for maximum overlap of their main beams over the 4-8 $\mathrm{GHz}$ range. Both transmitting (2.5' diameter) and receiving ( 3 ' diameter) antennas are equipped with ridged waveguide dual-polarized feeds. 


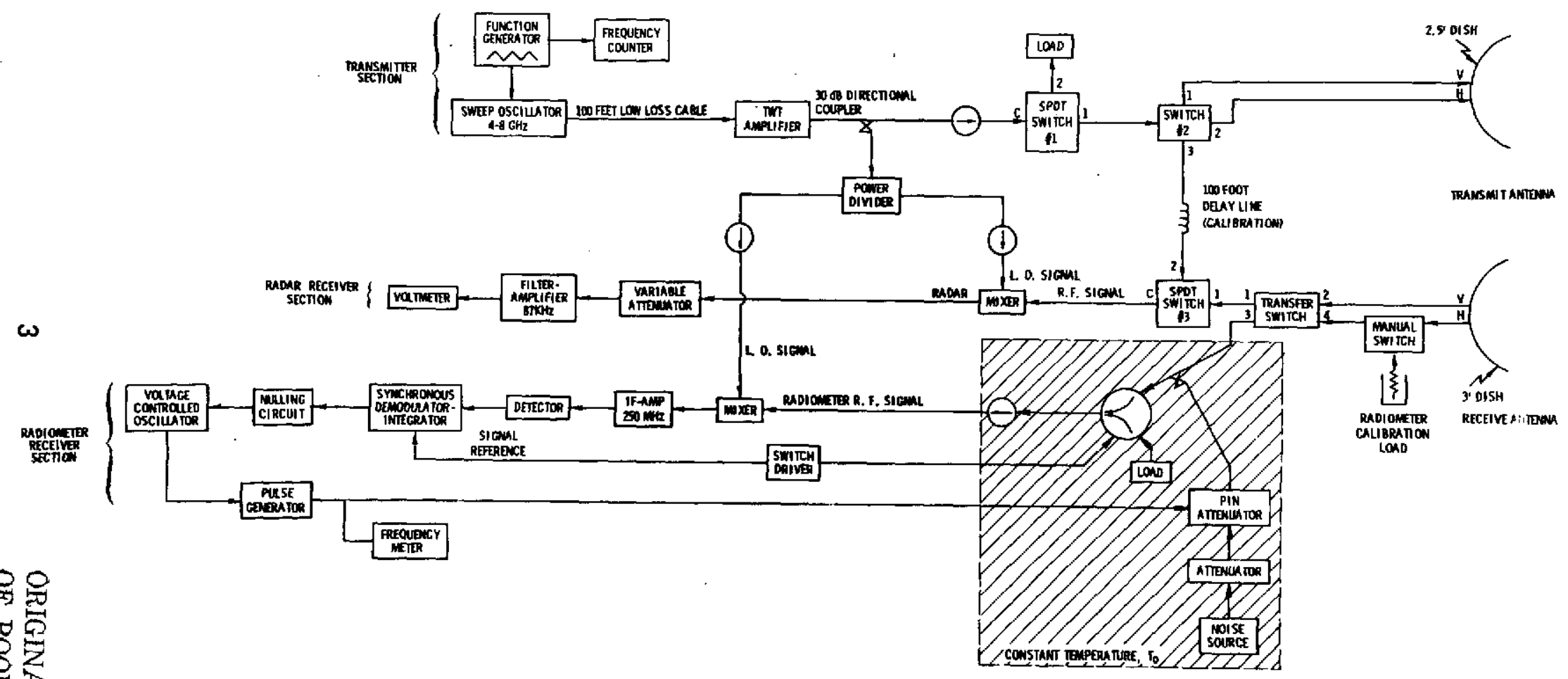

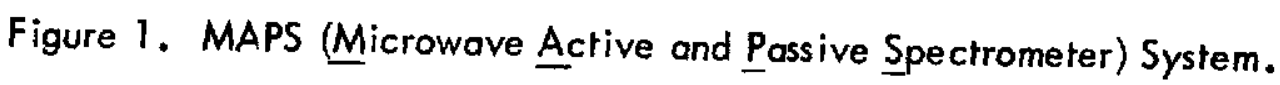


The antennas and some of the RF components are mounted atop a $75^{1}$ truck-mounted boom. Figure 2 is a photograph of the truck and the van housing the electronic control equipment. The operator can point at the target of interest at any incident angle between $0^{\circ}$ (normal) and about $75^{\circ}$ and at any az imuth angle. The FM-CW radar produces a return averaged over $400 \mathrm{MHz}$ for each of two orthogonal rece ived polarizations, one of which is the same os that transmitted. By properly switching the two polarization ports at the antenna feed of each of the two antennas, the scattering coefficient can be measured for all four linear polarization combinations. All switching modes are remotely controlled from the van; this capability insures that the multi-polarization and multi-frequency data gathered at a given look angle is indeed from the same target area. The radar system parameters are summarized in Table 1.

The choice of the $400 \mathrm{MHz}$ FM sweep-width was based on a compromise between spectral resolution and signal fading statistics. If the target area is assumed to be represented by a random collection of discrete independent scatterers, then the envelope of the received signal is a random variable with its amplitude described by a Rayleigh distribution [15]. Under these conditions the spacing between independent frequency somples is given by $[16,17]$ :

$$
\Delta F_{s}=\frac{150}{D} M H z
$$

where $D$ is the distance between the closest and farthest points (measured radially from the radar antenna) on that part of the illuminated cell contributing to the measured return. For an $F M-C W$ radar system, $D$ can be determined from geometrical considerations:

$$
D=R_{2}-R_{1}=h\left(\sec \theta_{2}-\sec \theta_{1}\right)
$$

where $h$ is the height of the antenna above the ground, $\theta$ is the look angle, and ${ }^{\theta} 2^{-\theta_{1}}=\beta$, the antenna beamwidth. At normal incidence only half the beamwidth should be considered. The above equation is valid as long as $D$ is smaller than the range resolution of the system, $\Delta R$, given by:

$$
\Delta R=R \frac{\Delta F_{I F}}{F}
$$

where $R$ is the range, $F_{I F}$ is the IF frequency and $\Delta F_{I F}$ is the IF bandwidth. $R$ can be determined from the system parameters and the recorded modulation frequency [14]. 


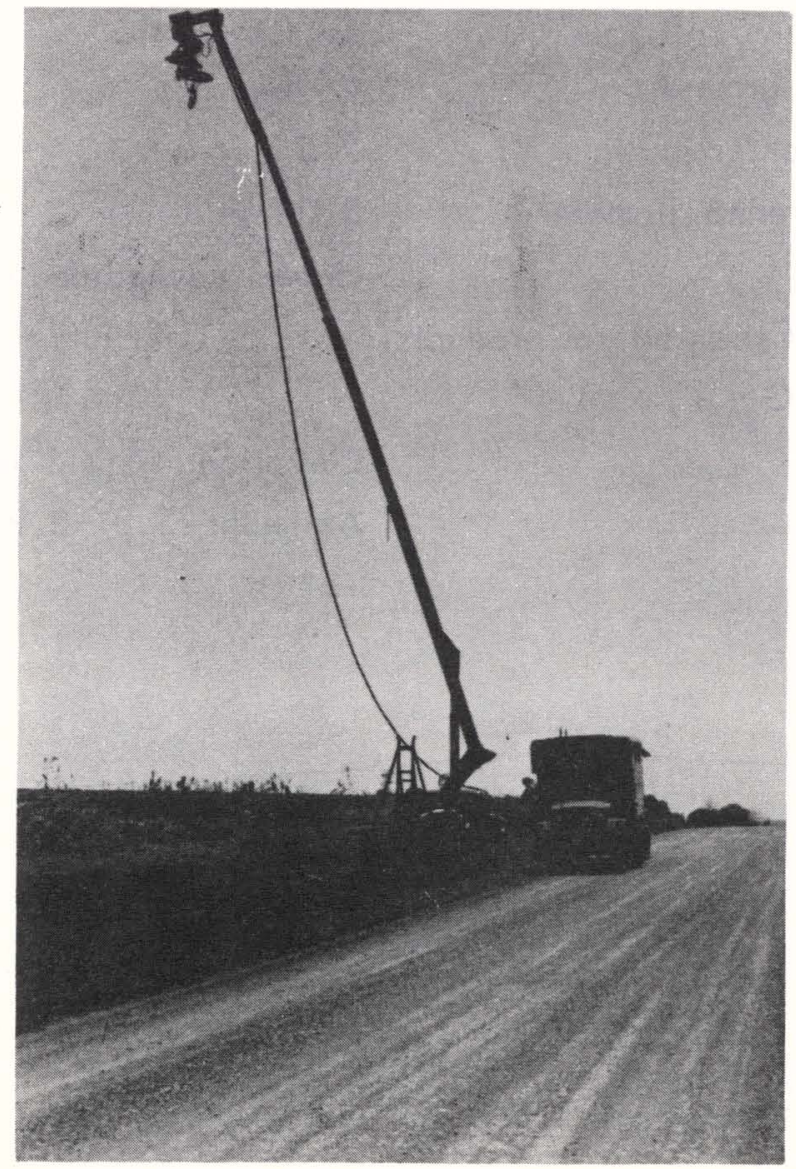

Figure 2. Photograph of the MAPS System During Operation. 


\section{TABLE 1.}

Type:

\section{FM-CW}

Modulating Wave Form:

Frequency:

FM Sweep: $\Delta F$

Transmitter Power:

Noise Figure:

Triangular

4-8 GHz

$400 \mathrm{MHz}$

5 watts

$18 \mathrm{~dB}$

IF Frequency: $F_{\text {IF }}$

IF Bandwidth: $\Delta F_{I F}$

Antennas:

Height above ground

Transmitting antenna diameter

Receiving antenna diameter

Feeds

Beamwidths of the patterns product

$$
\left(G_{T}(\theta, \phi) \cdot G_{R}(\theta, \phi)\right)
$$

\author{
67 feet \\ 2.5 feet \\ 3.0 feet \\ ridged waveguide, dual polarized
}

Elevarion: $4^{\circ}-3.1^{\circ}$ (over $4-8 \mathrm{GHz}$ )

Az imuth: $3.8^{\circ}-2.9^{\circ}$ (over $4-8 \mathrm{GHz}$ ) 
Moreover, Eq. (2) does not take into account contributions to $D$ by either the surface roughness or by sub-surface scatterers. At the larger look angles both effects may be neglected since $D$ is considerably larger than the surface height variations and the depth of penetration, but at normal incidence the value of D from Eq. (2) may be smaller than either of these two effects. If we assume an average antenna beamwidth (refer to Table 1 ) $B=3.5^{\circ}$ and $h=22 \mathrm{~m}$, then $D=1.1 \mathrm{~cm}$ at normal incidence which corresponds to a frequency spacing between independent samples, $\Delta F_{s}=13.63 \mathrm{GHz}$ ! An estimate of $D$ based on surface height variations and penetration depth, on the other hand, can be as much as $5-20 \mathrm{~cm}$ for bare soils (depending on the degree of roughness and the skin depth) and as much as $1.26 \mathrm{~m}$ (system range resolution) for tall agriculfural crops such as com and sorghum. Increasing the look angle, $\theta$, causes a rapid decrease in $\Delta F_{s}$ resulting in an increase in the number of independent samples, $N$, over the $400 \mathrm{MHz}$ sweep-width At $\theta=70^{\circ}$, for example, $\Delta F_{s}=40 \mathrm{MHz}$ and hence $N=10$. This clearly indicates that special care should be observed in the data analysis with regard to measurement precision. This is discussed further in section 3.

\subsection{Cal ibration Procedure}

Two types of calibration procedures were incorporated in this investigation:

(a) Delay Line Calibration: As shown in Figure 1, a 100' delay line cable is used to bypass the antennos via a pair of switches at the transmitter (port 3 of switch "2) and receiver (port 2 of switch \#3) lines. This, in effect, allowed us to internally calibrate the system in a closed-loop form independent of the antennas or the outside world; any slow, but acceptable, variations in the system performance would be calibrated out. The procedure was repeated before and after each data set (section 2.3), which corresponds to approximately 20 minutes.

(b) Luneberg Lens Calibration: An Emerson and Cuming Model 2B-109 Type 140 Luneberg Lens was used to convert the data gathered from relative to absolute values. The lens has a spherical cap reflective metallic surface subtending a spherical angle of $140^{\circ}$, thereby producing a reflectivity pattern which is a constan over a wide ongular (conical) range; the $3 \mathrm{~dB}$ points are at about $\pm 65^{\circ}$. The theoretical backscattering cross section of the Ecco Lens is given by: 


$$
\sigma=\frac{4 \pi^{3} r^{4}}{\lambda^{2}}
$$

where $r$ is the radius of the lens and $\lambda$ is the wavelength. Cross section data measured by the manufacturer indicate very close agreement with theory over the $4-8 \mathrm{GHz}$ band. This calibration procedure was repeated approximately every two weeks. In addition to using the lens as an "absolute" calibratar, any misalignments in the two antennas occurring during any two-week interval would have been observed. Fortunately, no such problems occurred.

Though metal spheres have been traditionally used to provide absolute cross section reference data, the Luneberg Lens has one main advantage: larger backscattering cross section. The lens used in this investigation is 9 " in diameter; its cross section at $6 \mathrm{GHz}$ is about $200(23 \mathrm{~dB})$ times larger than the cross section of a 9" diameter metal sphere $\left(\sigma_{\text {sphere }} \cong \pi r^{2}\right.$ for $r / \lambda>2$ ). The lens was hung from a long rod attached to a windmill; three strings tied to the outside dielectric frame around the lens are used to keep it in place. The stability of the measured return was observed to be betrer than $\pm 0.2 \mathrm{~dB}$. Upon moving the lens out of the antennas' main beam by the attached string, the signal level dropped by more than $40 \mathrm{~dB}$. This assured us that the windmill structure had no effect on the calibration data.

\subsection{Meosurements}

Two bare ground fields having very different surface textures were the subject of this investigation. Photographs of the two fields are shown in Figure 3. In terms of the wavelength $(3.75-7.5 \mathrm{~cm})$, the field in Figure $3 a$ can be considered "slightly rough" while the field in Figure $3 \mathrm{~b}$ is "very rough"; their respective RMS surface heights were $2.5 \mathrm{~cm}$ and $5.5 \mathrm{~cm}$.

Spectral response data were obtained from the two fields over a period of one month (August 72) at 2-3 day intervals. Each "set" of data consisted of measuring the radar return at 10 frequency points (each representing a $400 \mathrm{MHz}$ average) across the $4-8 \mathrm{GHz}$ band of incident angles of $0^{\circ}-70^{\circ}$ in $10^{\circ}$ steps for all polarization combinations: $H H, H V, W$ and $V H$. After the raw data was processed to determine the backscattering coefficient, $\sigma^{\circ}$, the $H V$ and $V H$ components were averaged together and, from there on, referred to as the "cross polarization" component. A total of 17 data sets were collected: 9 from the "slightly rough" field and 8 from the "very rough" field. 


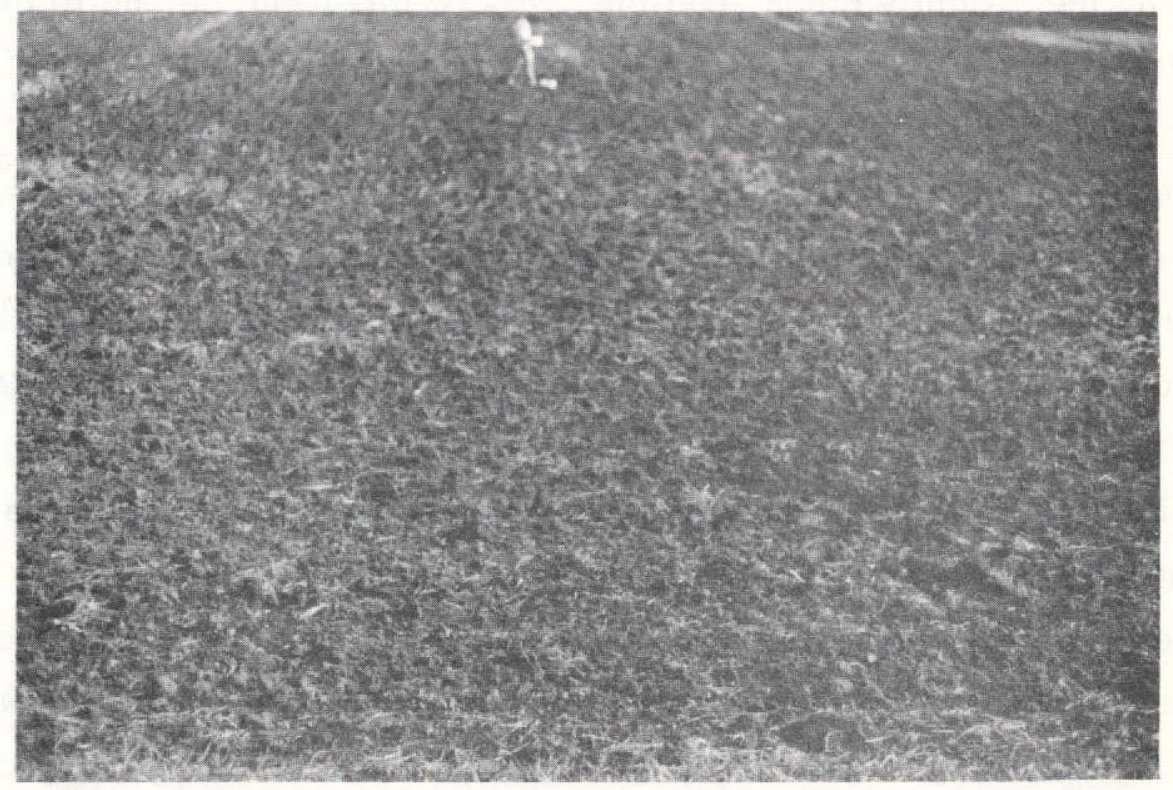

Figure 3a. Photograph of the "Slightly Rough" Field. Soil Type: Pawnee Clay Loam, RMS Surface Roughness $=5 \mathrm{~cm}$.

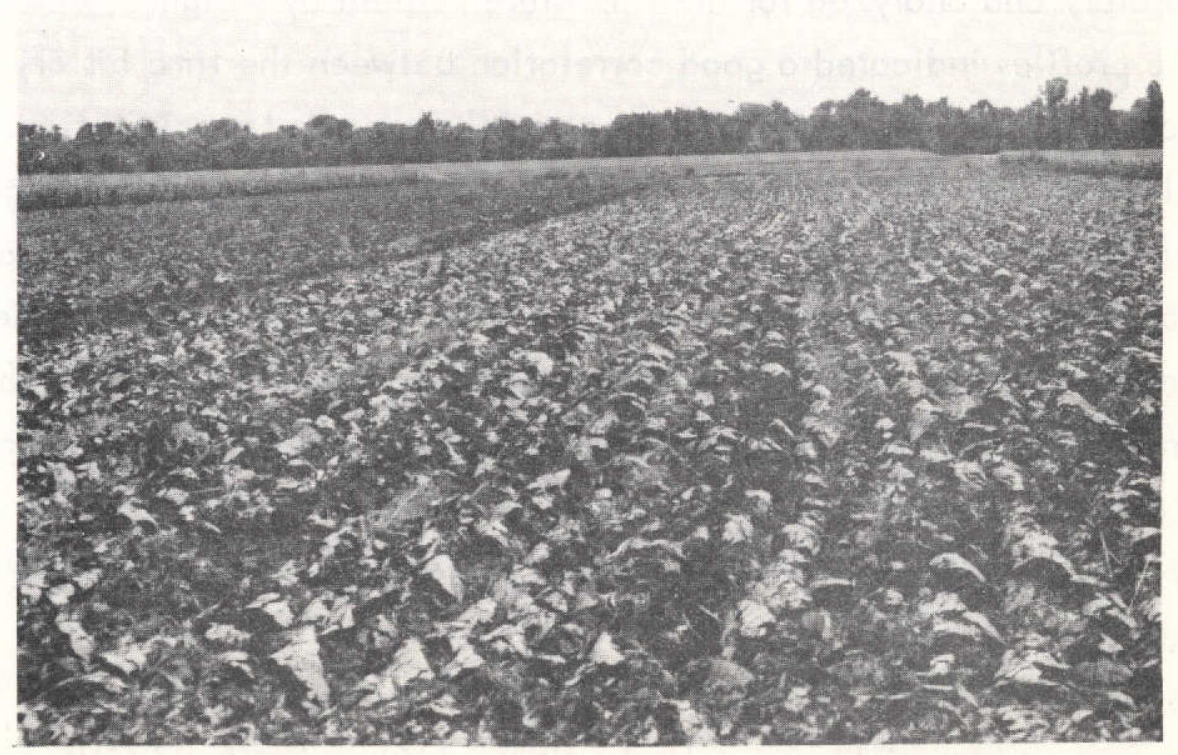

Figure 3b. Photograph of the "Very Rough" Field. Soil Type: Kimo Silty Clay Loam, RMS Surface Roughness $=11 \mathrm{~cm}$. 


\subsection{Ground Truth Data}

Both, the "slightly rough" and the "very rough" fields belong to the same family in terms of soil type; the former is classified as "Pawnee clay loam" while the later is classified as "Kimo silty clay loam". The "slightly rough" field had been plowed-over and later cultivated to break up the clods. The "very rough" field on the otherhand, was plowed-over while wet which caused its surface texture to look very coarse and "blobby" in shape. From surface height profiles taken with a surface-copying rod and photographs like those shown in Figure 3, the RMS surface heights were estimated to be about $2.5 \mathrm{~cm}$ for the field shown in Figure $3 a$ (peak to peak amplitudes between $6-9 \mathrm{~cm}$ ) and $5.5 \mathrm{~cm}$ for the field shown in Figure $3 \mathrm{~b}$ (peak to peok amplitudes between $16-20 \mathrm{~cm}$ ).

These estimates are based on relatively dry soil conditions; after each rain the surface texture of the slightly rough field was observed to smooth out while the texture of the very rough field was almost unaffected due to its high clay content.

Before each data set was recorded, two soil samples were usually collected from the field, one taken at a distance of about 10 feet from the road (near range) and another sample taken at a distance of about 100 feet from the road (far range). Each soil sample consisted of samples taken at each of four depth layers: $0-2 \mathrm{~cm}$, $2-5 \mathrm{~cm}, 5-9 \mathrm{~cm}$ and $9-15 \mathrm{~cm}$. The 8 samples were placed in plastic bags, taken to the laboratory and analyzed for the ir moisture content by weight. Analysis of the moisture profiles indicated a good correlation between the time history of the moisture contents measured in the far range and the recorded precipitation time history. The differences in moisture content between the near and far range samples were within 10\% of one another in all cases except 2 (out of 9). In general, the moisture content in the near range samples was consistently smaller than the content in the far range samples; the cause is attributed to the location of the ditch between the road and the near-range sampling spot. Since the distance from the road to the $0^{\circ}$ (normal incidence) cell seen by the antennas is approximately 26 feer, we decided to use only the far range moisture profile data as a measure of the moisture content in the field.

Measurements of the dielectric properties of several soil types as a function of moisture content by weight at $9 \mathrm{GHz}$ by Wiebe $[18]$ and at $5.87 \mathrm{GHz}$ and 9.375 $\mathrm{GHz}$ by Lundien [1I] were used to estimate the skin depth over the $4-8 \mathrm{GHz}$ region. 
At $4 \mathrm{GHz}$ the skin depth was calculated for $5 \%$ and $10 \%$ moisture content by weight to be about $8 \mathrm{~cm}$ and $4 \mathrm{~cm}$ respectively. Since the skin depth decreases with frequency and moisture content, it was decided to use the overage moisture content in the top $5 \mathrm{~cm}$ of the soil as a measure of the moisture content parameter. Using this definition, the range of moisture contents observed extends from $4.3 \%$ to $36 \%$ for the "slightly rough" field and $7.4 \%$ to $30.3 \%$ for the "very rough" field as shown in Table 2 .

\section{ANALYSIS OF THE RESULTS}

\subsection{Precision of Measurement}

If the instantaneous distribution for the fading signal voltage is assumed to be Rayleigh, then the overage output voltage (after square-law detection) from $\mathrm{N}$ independent samples is described by a chi-square distribution with $2 \mathrm{~N}$ degrees of freedom. The total number of samples, $N_{T}$ is the product of the number of measurements (or data sets) averaged, $N_{d^{\prime}}$ and the number of independent samples obtained by frequency averaging within each measurement, $N$ :

$$
\begin{aligned}
& N_{T}=N_{d} \cdot N \\
& N=\frac{\Delta F}{\Delta F_{s}}
\end{aligned}
$$

where $\Delta F$ is the measurement bandwidth and $\Delta F_{s}$ is the required frequency spacing between independent samples. In terms of the $400 \mathrm{MHz}$ sweep-width employed in making the measurements reported in this paper, $N$ has been calculated for each of the 8 look angles used and is shown in Table 3. At normal incidence D was assumed equal to twice the RMS surface heights; this appears to be a reasonable assumption in view of the discussion made in section 2.1. Between $10^{\circ}-40^{\circ}, \mathrm{Eq} .(2)$ was used while for the $50^{\circ}-70^{\circ}$ range Eq. (3) was used instead since in this range the IF bandwidth becomes the limiting factor on the range resolution of the system rather than the geometrical considerations expressed in Eq.(2). The total number of independent samples for a given moisture state and look angle, $N_{T}$, can now be obtained from the values of $N_{d}$ in Table 2 and $N$ (Table 3). 
TABLE 2. Distribution of measured data sets over moisture states. Moisture content is in $\%$ by weight over the top $5 \mathrm{~cm}$ of the soil surface, and $\mathrm{N}_{\mathrm{d}}=$ number
of data sets.

\begin{tabular}{c|ccccc|cccc}
\multicolumn{5}{c|}{ Slightly Rough Field } & \multicolumn{4}{c}{ Very Rough Field } \\
\cline { 2 - 9 } Moisture & 4.3 & 15.8 & 24.0 & 30.2 & 36.3 & 7.4 & 10.3 & 17.1 & 30.3 \\
$N_{d}$ & 3 & 3 & 1 & 1 & 1 & 3 & 1 & 1 & 3 \\
\hline
\end{tabular}

TABLE 3. Calculated values of $D, \Delta F$ (Eq. 1), and N (Eq . 6) as a function of look angle for $\Delta F=400 \mathrm{MHz}$ and 1200 $\mathrm{MHz}$.

\begin{tabular}{|c|c|c|c|c|}
\hline \multirow[b]{2}{*}{ Look Angle } & \multirow[b]{2}{*}{ D } & \multirow[b]{2}{*}{$\Delta F_{s}$} & \multicolumn{2}{|c|}{$\underline{N}$} \\
\hline & & & $\Delta F=400 \mathrm{MHz}$ & $\Delta F=1200 \mathrm{MHz}$ \\
\hline $0^{\circ}$-Slightly Rough & $5 \mathrm{~cm}$ & $\overline{3 \mathrm{GHz}}$ & 1 & $i$ \\
\hline $0^{\circ}$-Very Rough & $11 \mathrm{~cm}$ & $1.36 \mathrm{GHz}$ & 1 & 1 \\
\hline $10^{\circ}$ & $22 \mathrm{~cm}$ & $680 \mathrm{MHz}$ & 1 & 2 \\
\hline $20^{\circ}$ & $50 \mathrm{~cm}$ & $300 \mathrm{MHz}$ & 1 & 4 \\
\hline $30^{\circ}$ & $77 \mathrm{~cm}$ & $195 \mathrm{MHz}$ & 2 & 6 \\
\hline $40^{\circ}$ & $125 \mathrm{~cm}$ & $120 \mathrm{MHz}$ & 3 & 10 \\
\hline $50^{\circ}$ & $196 \mathrm{~cm}$ & $77 \mathrm{MHz}$ & 5 & 16 \\
\hline $60^{\circ}$ & $252 \mathrm{~cm}$ & $60 \mathrm{MHz}$ & 7 & 20 \\
\hline $70^{\circ}$ & $370 \mathrm{~cm}$ & $40 \mathrm{MHz}$ & 10 & 30 \\
\hline
\end{tabular}


By applying the method of confidence intervals, confidence limits around the estimated (measured) value of the scattering coefficient can be determined such that the probability that the true value is situated between these limits is equal to the confidence coefficient [19].

Following the procedure outlined by Fisz [19], upper and lower confidence limits (relative to the estimated value) corresponding to $\pm 25 \%$ probability intervals around the mean have been calculated (Figure 4) for each value of $\mathrm{N}_{T}$ shown in Table 3 from tabulated chi-square distributions with $2 \mathrm{~N}$ degrees of freedom. The $\Delta \mathrm{F}=$ $1200 \mathrm{MHz}$ entry in Table 3 will be discussed in the next section.

The measured scattering coefficient is a function of five variables: 1) soil rype and surface roughness , 2) moisture content, 3) frequency, 4) look angle, and 5) polarization. The objective of this study is to determine the dependence of the scattering coefficient on the target parameters ( 1 and 2 ) as a function of the sensor parameters $(3-5)$.

\subsection{Frequency Response}

Though the effect of frequency on the radar response to moisture content is discussed in section 3.4, it was felt necessary to include in this section samples of the frequency response over the $4-8 \mathrm{GHz}$ range in order to illustrate the effect of fading on the measured scattering coefficient. In Figure 5, the magnitudes of the measured scattering coefficients for two extreme cases are shown: 1) $0^{\circ}$ data from the $24 \%$ moisture field for which $N_{T}=1$ (Figure $5 a$ ) and 2) $70^{\circ}$ data from the $15.8 \%$ moisture field for which $N_{T}=30$ (Figure $5 \mathrm{~b}$ ). With a probability of $50 \%$, the true spectral responses fall within the region between the dashed curves. For the $N_{T}=$ 30 case shown in Figure $5 \mathrm{~b}$, the confidence limits extend about $\pm .5 \mathrm{~dB}$. The solid curve represents one possible solution; without the guidance of some physical model which can predict the general behovior of the scattering coefficient as a function of frequency, the only possible assumption that can be made is that the slope of the spectral response would not be expected to very rapidly with frequency. In any event, the $\mathrm{ldB}$ width of the confidence region makes it possible to use the data to establ ish some general trends since it is comparable in magnitude to the expected accuracy of airborne or high resolution spaceborne systems. For the one independentsample case shown in Figure $5 a$, on the other hand, the $50 \%$ confidence intervals 


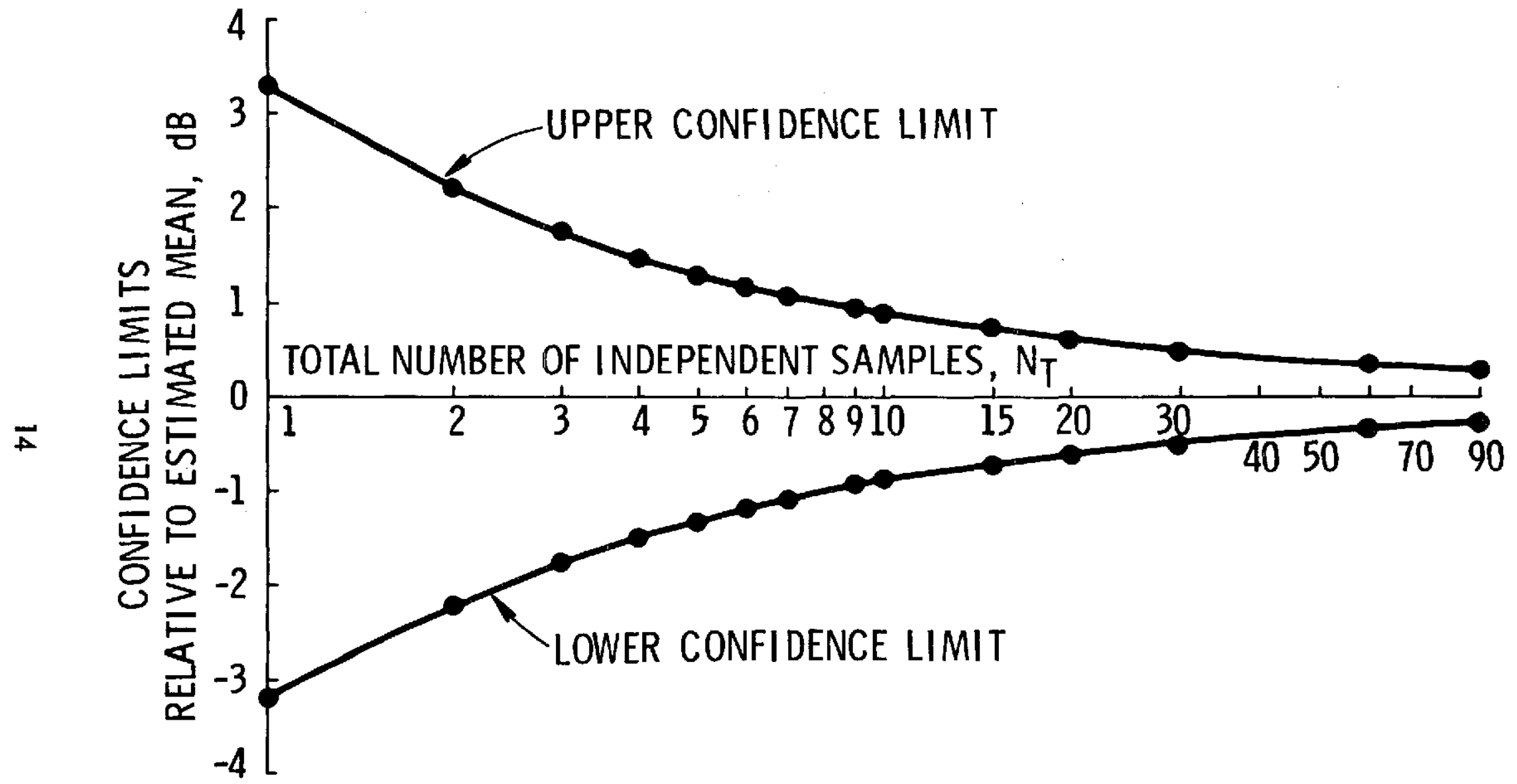

Figure 4 . 50\% confidence interval as a function of number of independent samples. 


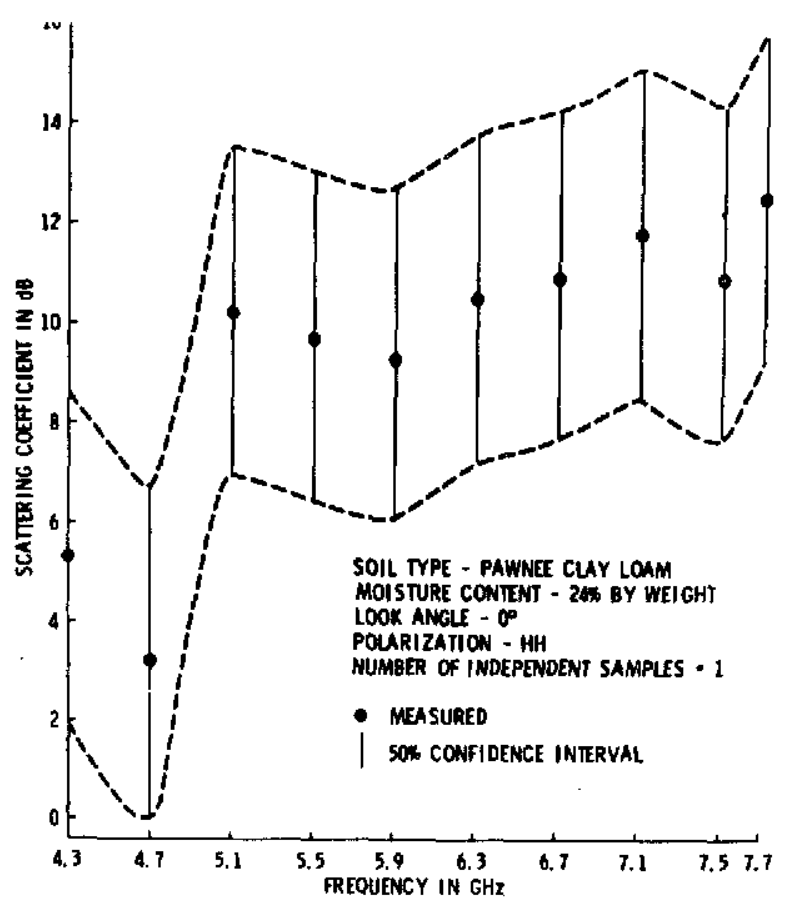

$5 a$

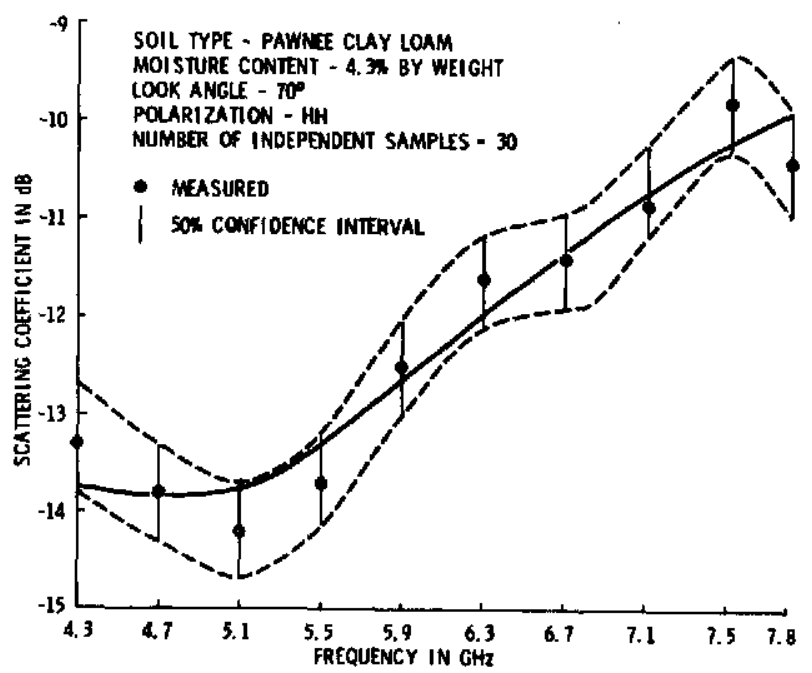

$5 b$

Figure 5. Scattering coefficient as a function of frequency for Pawnee Clay Loam at look angles of a) $0^{\circ}$ and b) $70^{\circ}$. Note that the ordinate scale in $5 a$ is twice the scale in $5 b$. 
extends from $+3.3 \mathrm{~dB}$ above to $3.2 \mathrm{~dB}$ below the measured estimate, thereby making it very difficult to utilize the duta effectively.

In an effort to reduce the variability, particularly at the smaller look angles, $\Delta F$ was increased from $400 \mathrm{MHz}$ to $1.2 \mathrm{GHz}$ (refer to Table 3); the new center frequencies are $4.7 \mathrm{GHz}, 5.9 \mathrm{GHz}$ and $7.1 \mathrm{GHz}$. Note that no improvement in terms of the number of independent samples is gained at normal incidence, but considerable improvement is achieved at the larger look angles.

\subsection{Look Angle Response}

\subsubsection{Slightly Rough Field}

Two moisture states $(4.3 \%$ and $30.2 \%$ ) have been chosen to illustrate the angular response of the scattering coefficient at $4.7 \mathrm{GHz}$ and $7.1 \mathrm{GHz}$ as shown in Figures $6 a-6 d$. Within the $50 \%$ confidence intervals associated with the measured data points, smooth curves have been drawn. The following major observations can be made. Whereas the $\mathrm{HH}$ and $\mathrm{VV}$ angular responses of the $4.3 \%$ moisture content state (Figures $6 a$ and $6 b$ ) exhibit slow exponential decays (total dynamic range between $0^{\circ}$ and $70^{\circ}$ is less than $12 \mathrm{~dB}$ ), the angular responses of the $30 \%$ moisture content states (Figures $6 \mathrm{c}$ and $6 \mathrm{~d}$ ) appear to exponentially decrease very fast between normal incidence and about $30^{\circ}$ and to level off at the higher angles. Furthermore, the total range has increased to more than $20 \mathrm{~dB}$. The increase in moisture content not only influences the dielectric properties of the soil, but is also causes the surface texture to appear smoother to the incident wave. The unexpectedly small magnitudes of the measured $0^{\circ}-7.1 \mathrm{GHz}$ scattering coefficients in Figure $6 \mathrm{~b}$ (relative to $10^{\circ}$ ) are probably attributed to a smaller moisture content and different soil structure due to the proximity of the ditch (refer to section 2.4). Though this effect is not as pronounced at $4.7 \mathrm{GHz}$ (Figure $6 \mathrm{a}$ ), the fact that the magnitudes at $0^{\circ}$ and $10^{\circ}$ are comparable supports the above explanation.

\subsubsection{Very Rough Field}

The surface texture of the very rough field is very coarse (twice the RMS surface roughness $=11 \mathrm{~cm}$ ) in terms of the wavelength even at the lower end of the 4-8 GHz band $(7.5-3.75 \mathrm{~cm}$ in wavelength). Unlike the Pawnee clay loam soil discussed in the previous section, the addition of water to the Kimo silty clay loam (1.18" of rain were recorded a few hours prior to recording the $30 \%$ moisture data set) did not smooth-out the surface texture due to its higher clay content. 


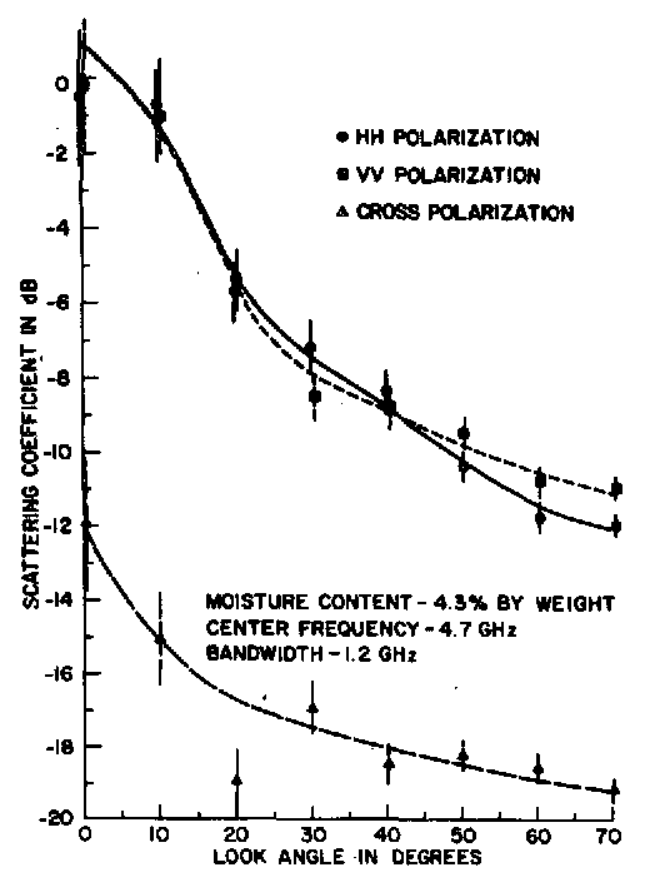

$6 a$

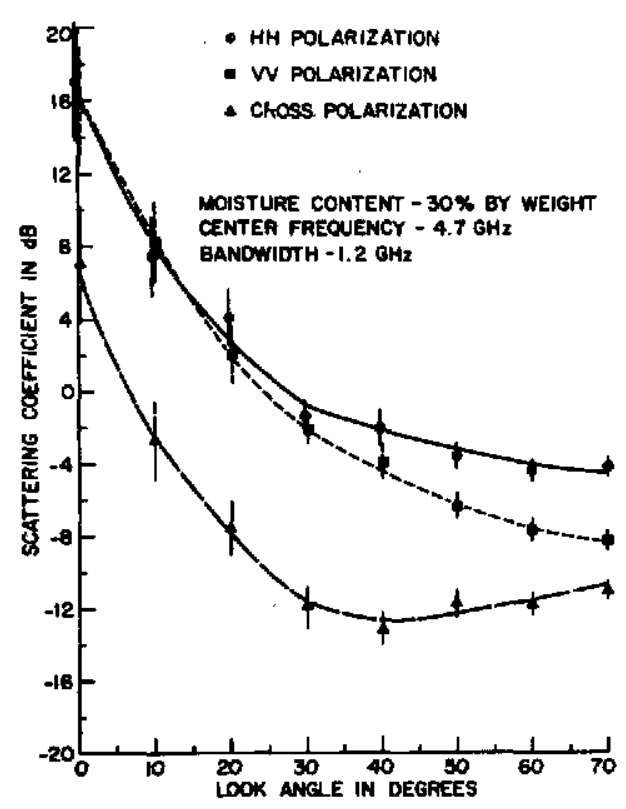

$6 c$

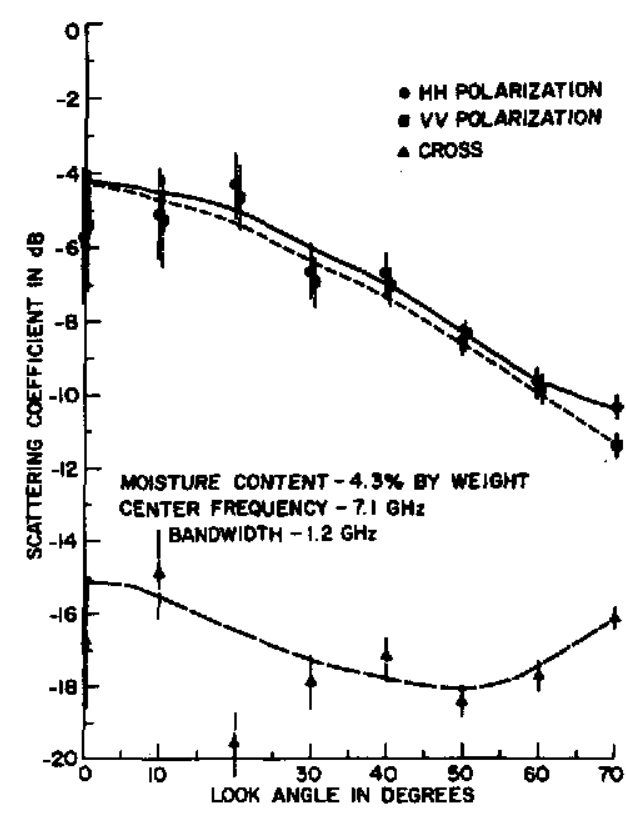

$6 b$

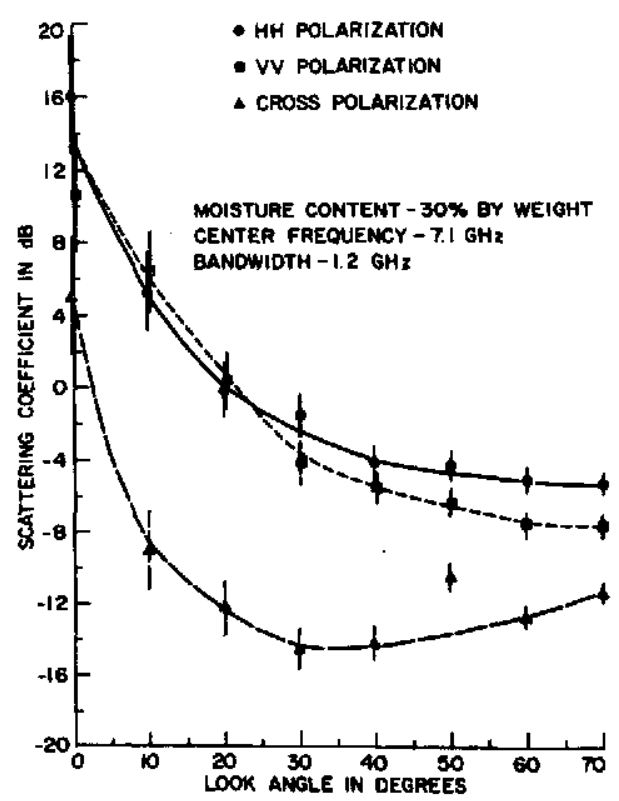

6d

Figure 6. Scattering coefficient as a function of look angle. Soil type = Pawnee Clay Loam, RMS surfoce height $=2.5 \mathrm{~cm}$. a) $4.7 \mathrm{GHz}, 4.3 \%$ moisture, b) $7.1 \mathrm{GHz}, 4.3 \%$ moisture, c) $4.7 \mathrm{GHz}, 30 \%$ moisture, and d) $7.1 \mathrm{GHz}, 30 \%$ moisture. 
Figures $7 a-7 d$ present the same type of information shown earlier in Figure 6, except now, no $0^{\circ}$ data is reported. The presence of a power line between the road and the very rough field did not permit us to park the truck as close to the edge of the field as we did with the slightly rough field. Hence, the illuminated cell at normal incidence was very close to the ditch between the field and the road. As suspected, the $0^{\circ}$ data exhibited wild variations (in comparison to the rest of the data including $0^{\circ}$ data from the slightly rough field) between different dara sets taken under the same conditions but from different illuminated cells. This is due to the nonuniform influence of the ditch on the edge of the field (in terms of moisture content).

\subsection{Moisture Content Response}

\subsubsection{Slightly Rough Field}

Figures $8 \mathrm{a}, 8 \mathrm{~b}$ and $8 \mathrm{c}$ show plots of the $\mathrm{HH}$ scattering coefficient as a function of soil moisture content by weight at $4.7 \mathrm{GHz}, 5.9 \mathrm{GHz}$ and $7.1 \mathrm{GHz}$, respectively. The points shown were extracted from "best fit angular response curves" similar to those shown in Figures 6 and 7. Each figure includes plots as four look angles, $10^{\circ}$ through $70^{\circ}$ in $20^{\circ}$ steps. Two major observations are apparent. First, the linearportion of the family of curves seems to be between about $15 \%$ and $30 \%$ moisture content; at low levels of moisture content, the response is "slow" and at very high moisture levels, there is a tendency for "slope reversal". Second, as the microwave frequency is increased from $4.7 \mathrm{GHz}$ to $7.1 \mathrm{GHz}$, the moisture range of the linear portion of the curves increases. At $4.7 \mathrm{GHz}$ the $10^{\circ}$ curve continues to increase (though slowly) as the moisture content is increased beyond $30 \%$, the $30^{\circ}$ and $50^{\circ}$ curves reverse slopes and the $70^{\circ}$ curve appears to saturate. At $7.1 \mathrm{GHz}$ the $10^{\circ}$ curve assumes a relatively sharp slope and the $30^{\circ}, 50^{\circ}$, and $70^{\circ}$ curves have recovered the ir $4.7 \mathrm{GHz}$ slope reversal effect but their overall slope berween $15 \%$ and $36 \%$ moisture has decreased.

A possible explanation for the decrease in the magnitude of the scattering coefficient as the moisture content increased beyond $30 \%$ is that the effect of rain on the soil caused the surface to appear "smooth" in terms of the wavelength. The $36 \%$ moisture data was collected a few hours after a reported 2.83 " of rain and the $30 \%$ moisture data was collected three days later. The smoothing effect of rain caused the backscatter return to decrease at $4.7 \mathrm{GHz}$, but as the frequency was 


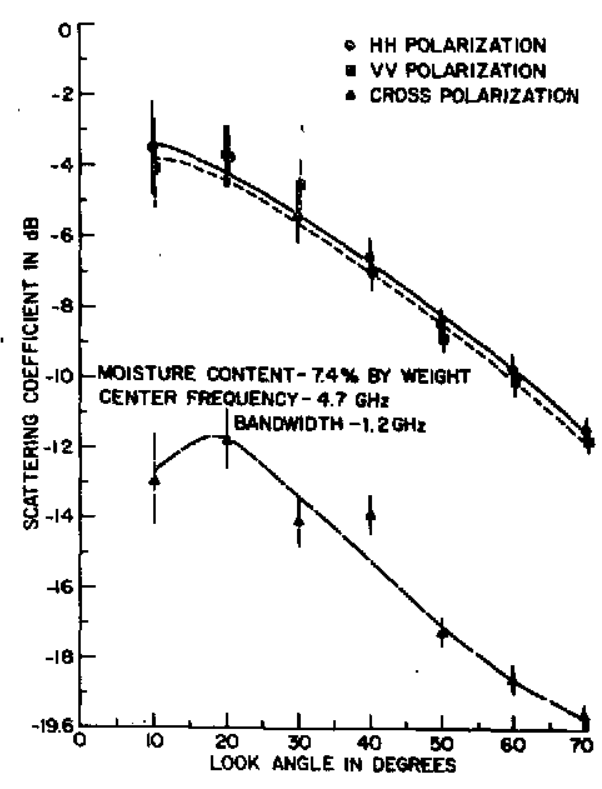

$7 a$

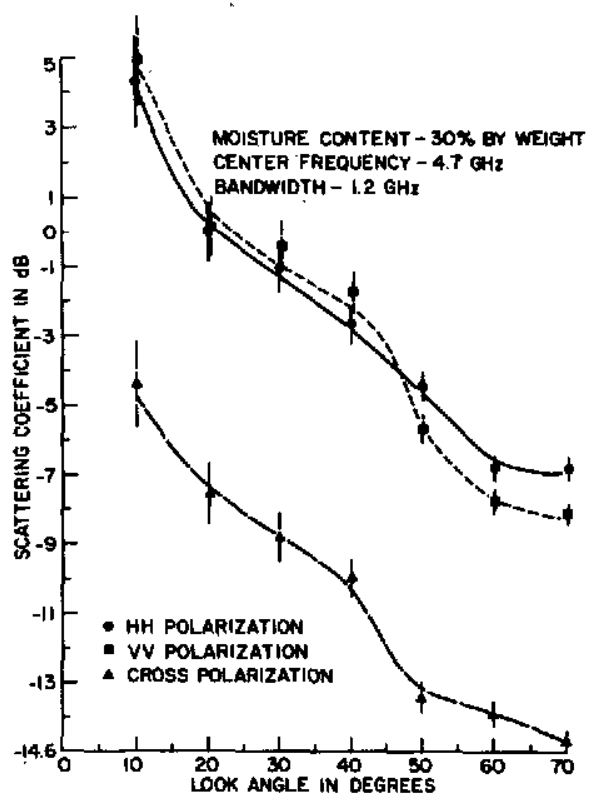

$7 c$

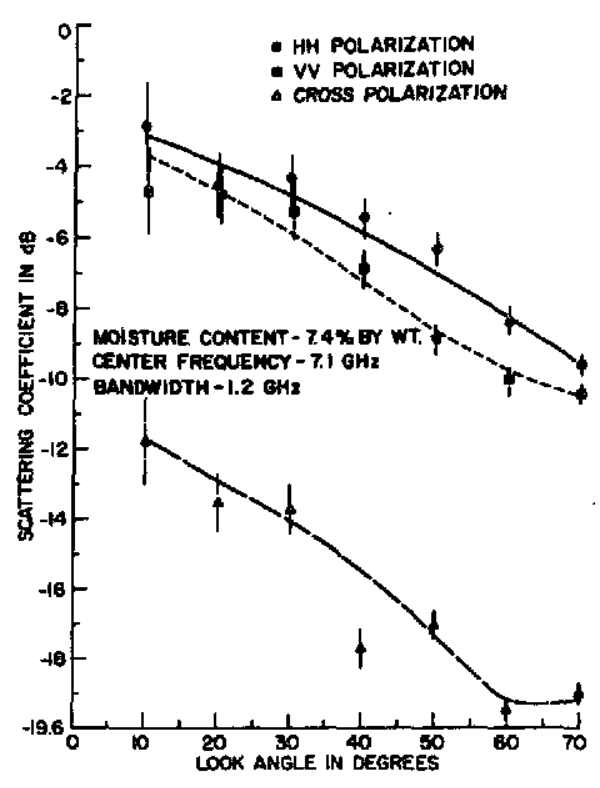

ðb

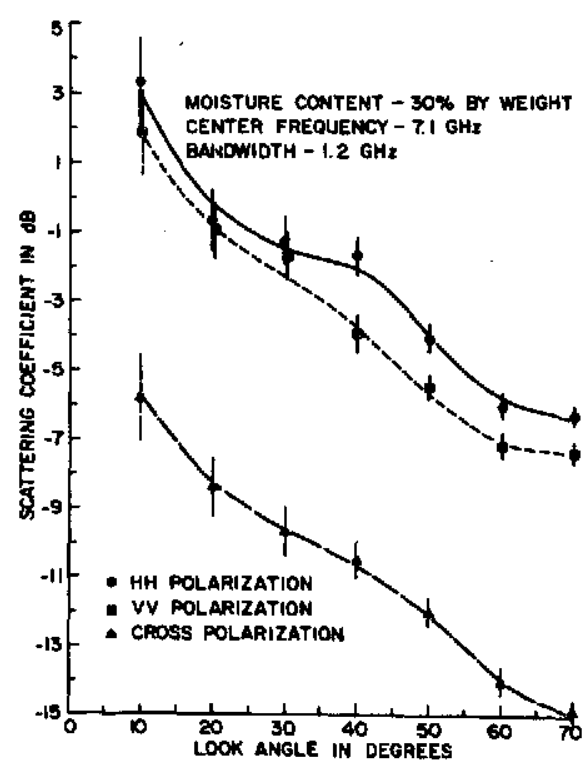

7d

Figure 7. Scattering coefficient as a function of look angle. Soil type = Kimo Silty Clay Loom, RMS surfoce height $=5.5 \mathrm{~cm}$. a) $4.7 \mathrm{GHz}, 7.4 \%$ moisture, b) $7.1 \mathrm{GHz}, 7.4 \%$ moisture, c) $4.7 \mathrm{GHz}, 30 \%$ moisture, and d) $7.1 \mathrm{GHz}, 30 \%$ moisture. 
increased to $5.9 \mathrm{GHz}$ and $7.1 \mathrm{GHz}$, the surface roughness increased enough to make the surface look "rough" again. We should also keep in mind that increasing the look angle is equivalent to smoothing the surface which explains the apparent successive disappearance of the slope reversal effect as the frequency increased from $4.7 \mathrm{GHz}$ to $7.1 \mathrm{GHz}$.

\subsubsection{Very Rough Field}

The measurements obtained from the $5.5 \mathrm{~cm}$ RMS surface roughness field cover a narrow range of moisture contents $(7.4 \%-30.3 \%)$ in comparison to the slightly rough field described above. Figure 9 shows plots similar to those shown earlier in Figure 8. Before describing the character of the moisture response, it should be noted that the analys is is based on only 4 moisture states; hence all conclusions drawn will be of a general and comparative nature.

Several interesting patterns are apparent in Figure 9. Af $4.7 \mathrm{GHz}$ a dip appears to develop in the mid-moisture range as the look angle is increased from $10^{\circ}$ to $70^{\circ}$, at $5.9 \mathrm{GHz}$ the dip exists at all the look angles, and at $7.1 \mathrm{GHz}$ the dip has become very pronounced. The presence of such a dip is completely unexpected if we adopt the simplistic argument that the addition of water to the soil increases the real and imaginary parts of the dielectric constant which in turn increase the magnitude of the reflection coefficient and likewise the magnitude of she scattering coefficient. Obviously, the answer lies in the complex scattering mechan isms governing the wave interaction with the clay "blobs" and the background surface. Furthermore, according to measured values of the complex dielectric constant as a function of moisture content of soil types (clay family) similar to those used in this investigation by Wiebe [18] at a slightly higher frequency, $9 \mathrm{GHz}$, the calculated increase in the power reflection coefficient (Figure 10) due to increase in moisture content from $16 \%$ to $30 \%$ is about $3.2 \mathrm{~dB}$ at normal incidence. The slightly rough surface model proposed by Peake [20] predicts a comparable figure over the range of dielectric constant values considered above. Over the same moisture content range, the data reported in this paper indicates an increase at a look angle of $10^{\circ}$ as small as $4 \mathrm{~dB}$ (at $4.7 \mathrm{GHz}$ ) for the very rough field to as large as $9.8 \mathrm{~dB}$ (at $4.7 \mathrm{GHz}$ ) for the slightly rough field. This is a clear example of the interdependence of moisture and surface and sub-surface roughness.

The position of the dip shown in Figure 9 appears to move toward lower moisture content levels as the frequency is increased, thereby increasing the moisture range of the linear portion of the curves. 


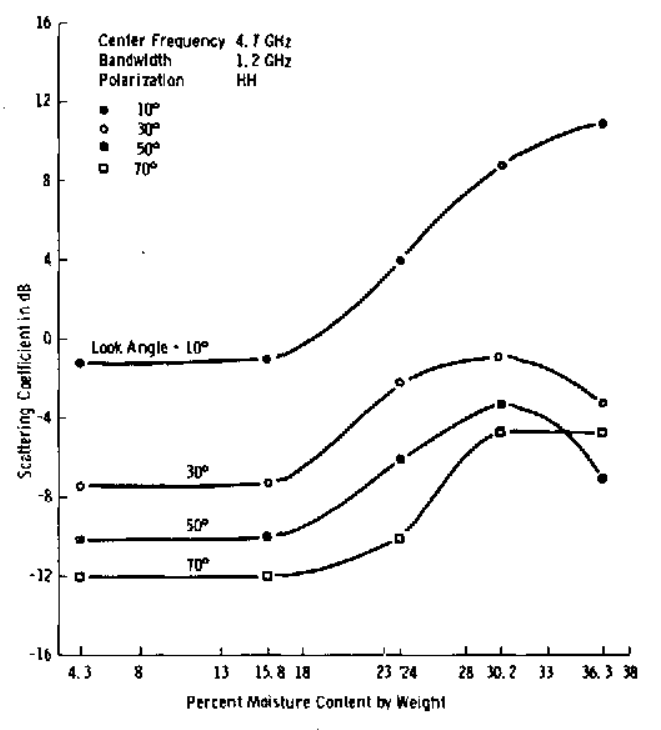

$8 a$

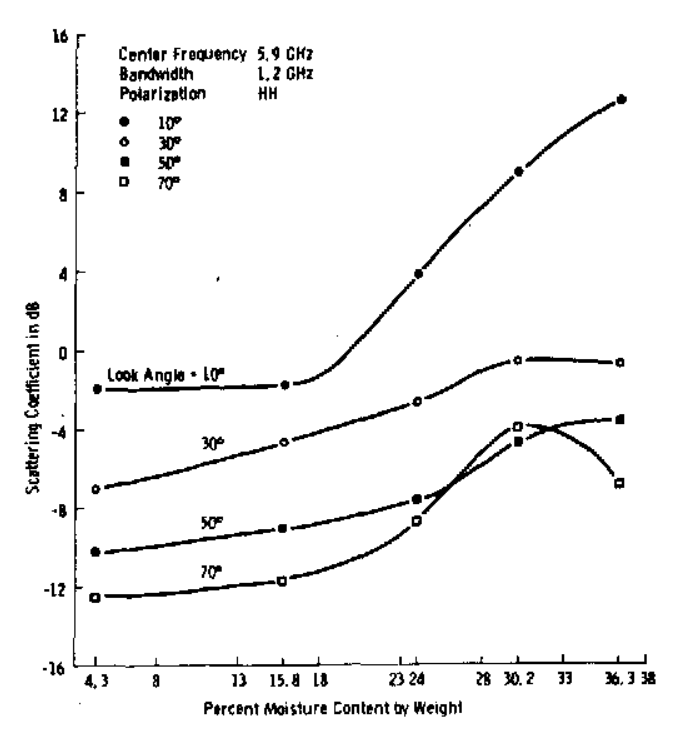

$8 b$

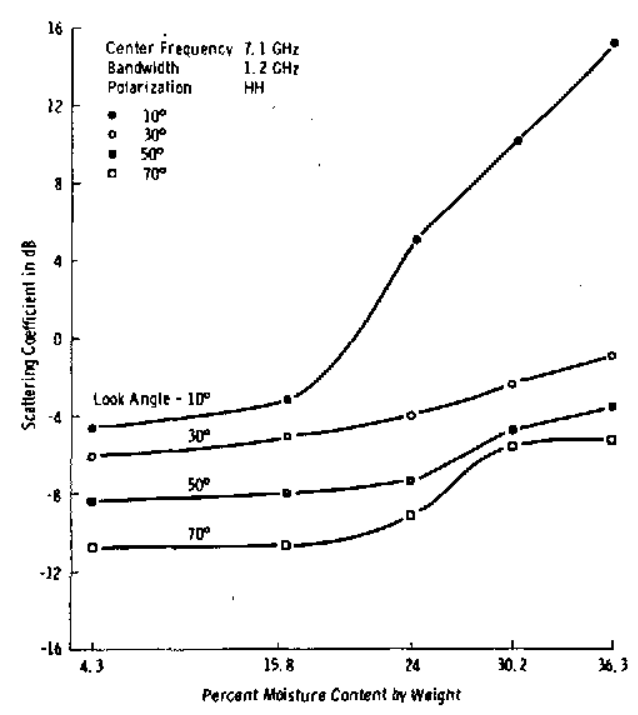

$8 c$

Figure 8. Scattering coefficient as a function of moisture content. Soil type $=$ Pawnee Clay Loam, RMS surface height $=2.5 \mathrm{~cm}$. a) $4.7 \mathrm{GHz}$, b) $5.9 \mathrm{GHz}$, and c) $7.1 \mathrm{GHz}$. 

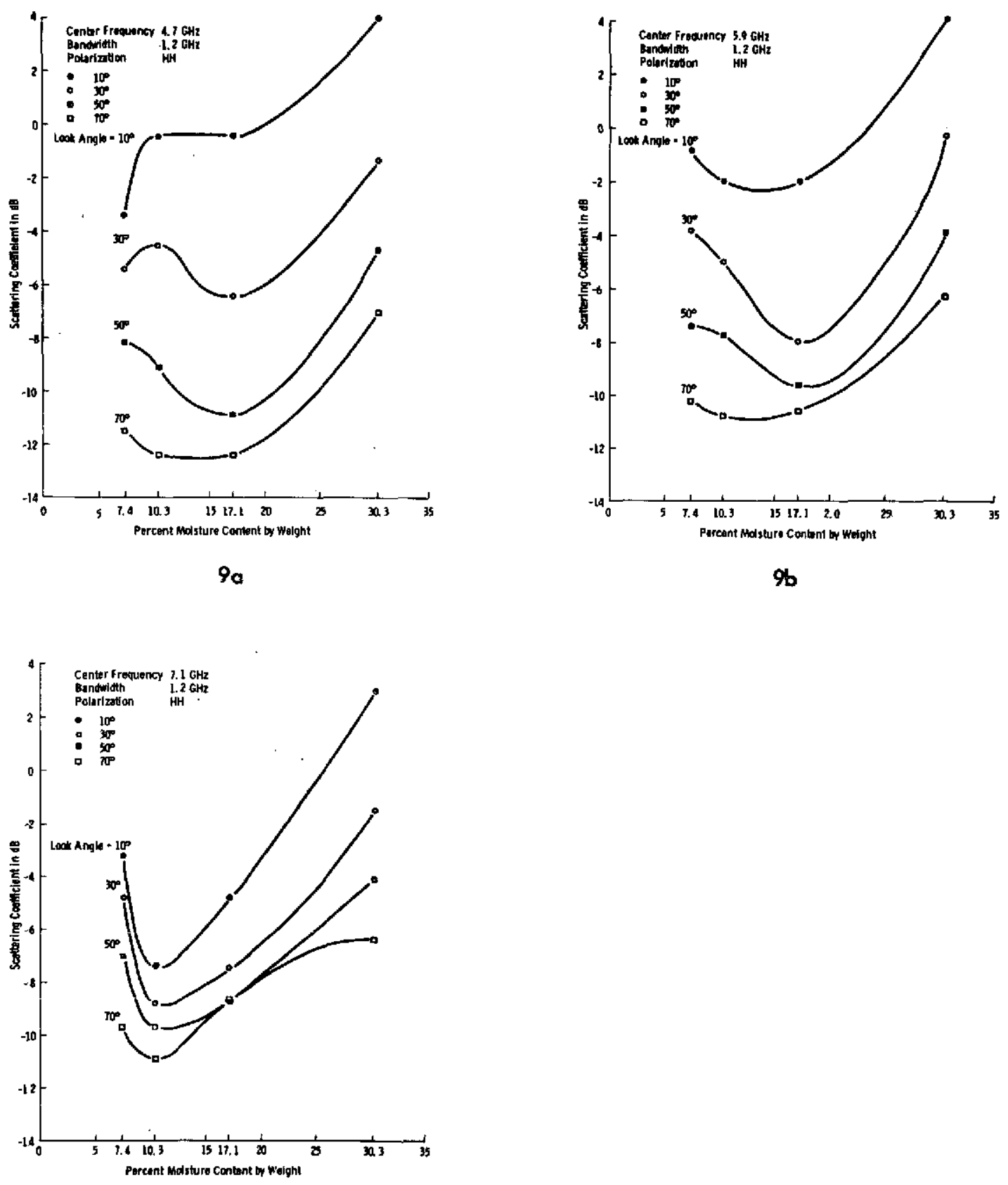

$9 c$

Flgure 9. Scattering coefficient os a function of moisture content. Soil typo = Kimo Silty Cloy Loam, RMS surface height = $5.5 \mathrm{~cm}$. a) $4.7 \mathrm{GHz}$, b) $5.9 \mathrm{GHz}$, and c) $7.1 \mathrm{GHz}$. 


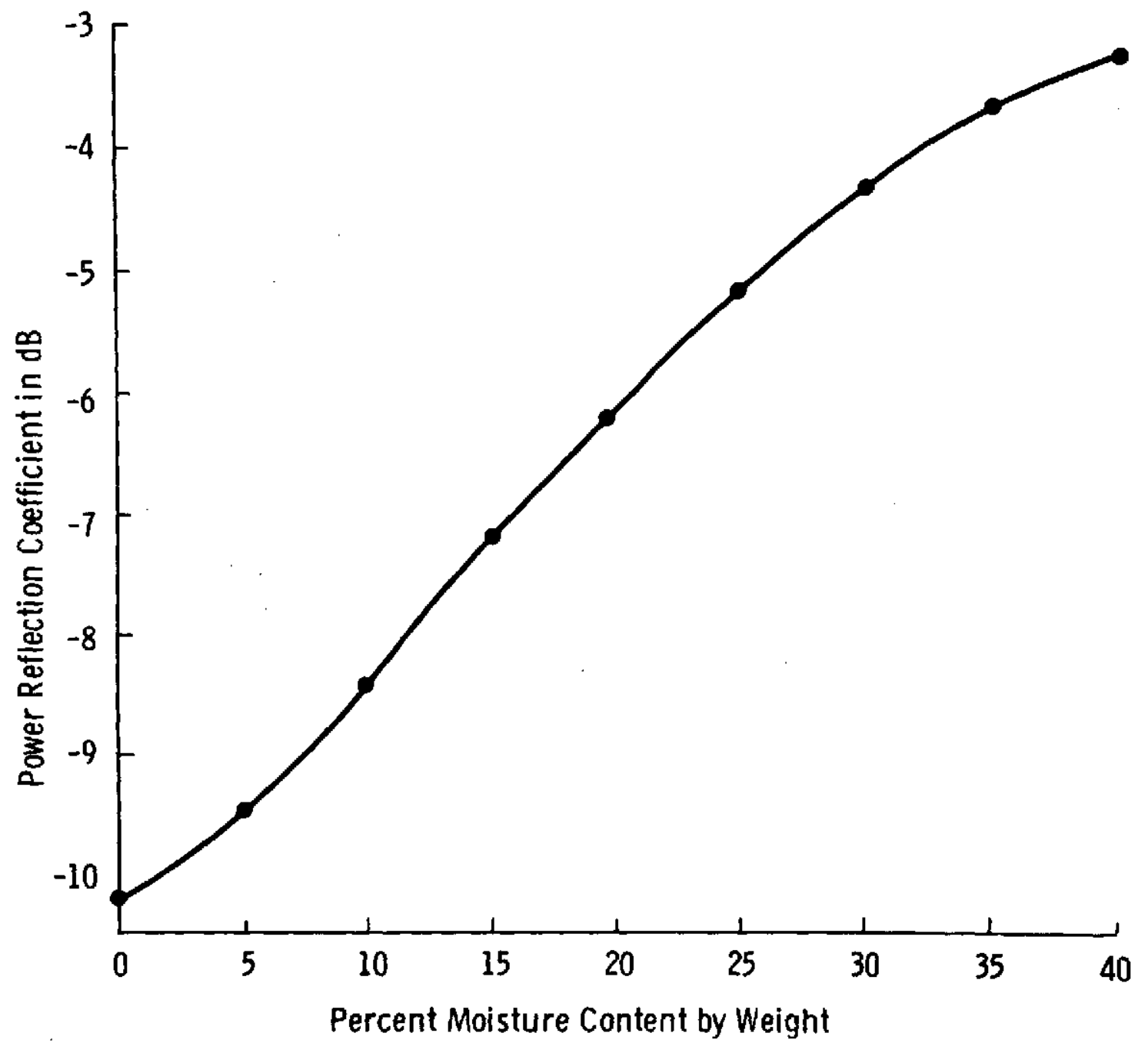

Figure 10. Power reflection coefficient as a function of soil moisture at normal incidence (bosed on dielectric constant data from Wiebe [18]). 


\section{PRELIMINARY DESIGN CRITERIA}

Since the radar return responds to both surface and sub-surface roughness and to moisture content, different design criteria can be postulated depending on the objectives and the sophistication level of the remote sensing package. If, for example, the objective is to determine temporal change in soil moisture through repetitive coverage of a given area, then soil type would not be a variable any more and therefore the choice of the radar parameters would be made on the bas is of maximum slope ( $\Delta \sigma^{\circ} / \Delta$ moisture). On the other hand, if the objective is to map soil moisture content from a single mission, and no collaborative data on soil type or condition is available (such as from photography), then it is imperative that the choice of sensor parameters be made such that the difference in the scattering coefficient due to soil type and surface roughness is minimized. In this section the major trends will be discussed.

Figures $11 \mathrm{a}, 11 \mathrm{~b}$ and $11 \mathrm{c}$ contain plots of the soil moisture response expressed in terms of the slope of the linear portion of the curves shown in Figures 8 and 9 (about $16 \%$ to $30 \%$ ) as a function of look angle at $4.7 \mathrm{GHz}, 5.9 \mathrm{GHz}$, and 7.1 $\mathrm{GHz}$, respectively. We may first observe that the slightly rough field is more frequency sensitive than its counterpart, the very rough field, not so much in terms of the slope of the moisture response curves as a function of angle but more so in terms of the magnitude (compare for example $\mathrm{HH} 4.7 \mathrm{GHz}$ and $\mathrm{HH} 5.9 \mathrm{GHz}$ curves for the two fields). Over the mid-range of look angle $30^{\circ}-50^{\circ}$, the $\mathrm{HH}$ response indicates a minimum for the slightly rough field while it indicates a maximum for the very rough field; the difference between the two responses is minimal at $4.7 \mathrm{GHz}$ but it grows rapidly with frequency.

The two fields appear very similar in terms of their moisture responses (though their absolute scattering coefficients at a given moisture level may be very different) in the $20^{\circ}-30^{\circ}$ and $50^{\circ}-60^{\circ}$ angular ranges for $\mathrm{HH}$ polarization and in the $15^{\circ}-30^{\circ}$ range for $V V$ polarization.

\section{CONCLUDING REMARKS}

The results presented in the preceding sections represent a small step towards a quantitative understanding of the complex mechanisms governing the rador response 


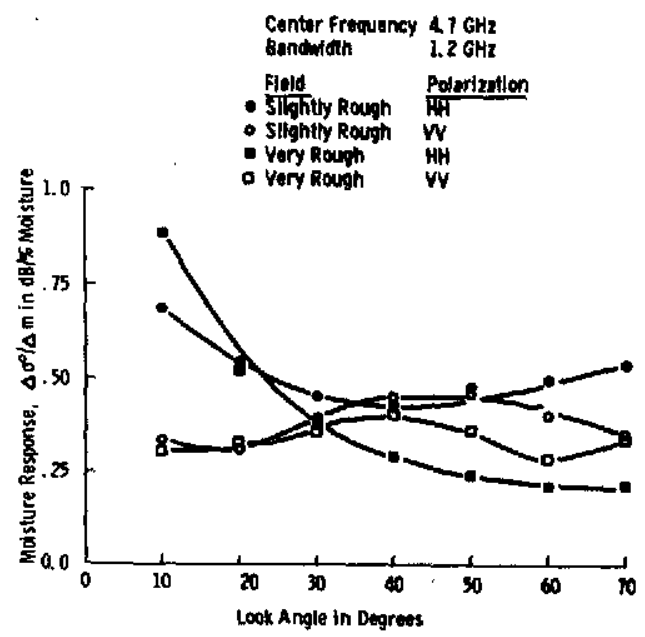

11a

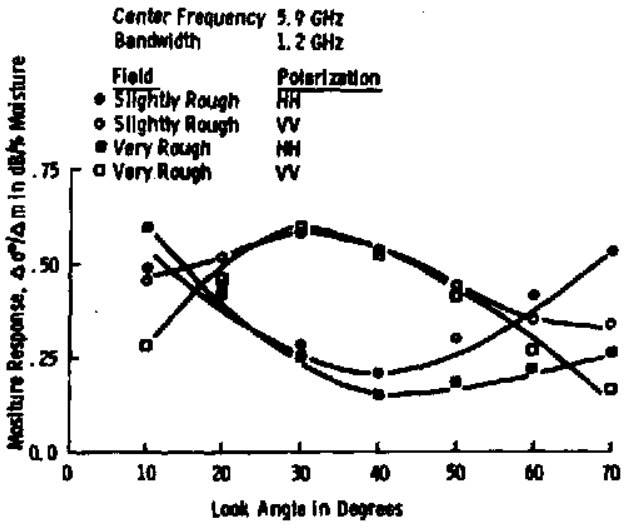

$11 \mathrm{lb}$

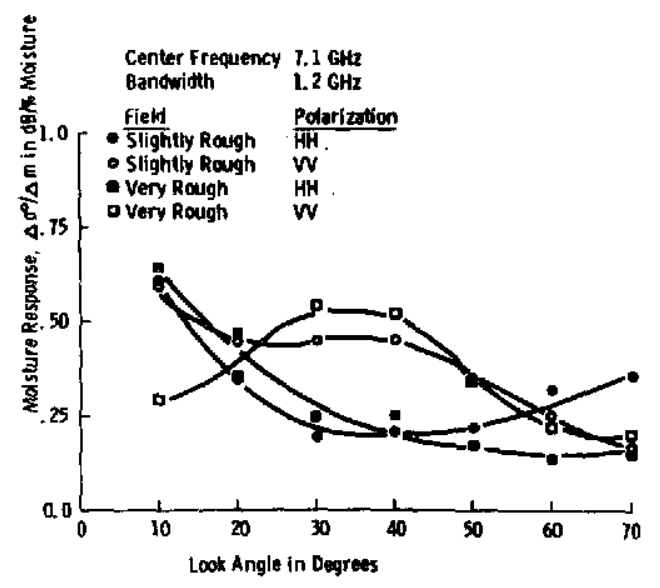

lle

Figure 11. Scattering coefficient response to soil moisture content, $\Delta \sigma \% \Delta m$ ( $\Delta m$ is the change in moisture content in units of \% by weight) as a function of look angle at a) $4.7 \mathrm{GHz}$, b) $5.9 \mathrm{GHz}$ and c) 7.1 $\mathrm{GHz}$. 
from bare ground as a function of surface roughness and moisture content. For the most part, this paper has posed more questions that it has answered which affirms the need for more analytical studies and experimental measurements of the radar response over a wide range of the various sensors (particularly frequency) and target parameters, under natural conditions, and supported by adequale ground truth information. 


\section{REFERENCES}

[1] Robinove, C.J., "Remote Sensing Applications in Hydrology," Proceedings 4th International Symposium on Remote Sensing of Environment, University of Michigan, Ann Arbor, 1966.

[2] Linsley, R. K., Choirman of the "Meeting of AGU Committee on Status and Needs in Hydrology," AGU Transactions, vol. 45, no. 4, pp. 693.

[3] Leighty, R.D., "Remote Sensing for Engineering Investigation of Terrain," Proceedings 5 th International Symposium on Remote Sensing of Environment, University of Michigan, Ann Arbor, 1968.

[4] Gates, D. M., "Characteristics of Soil and Vegetated Surfaces to Reflected and Emitted Radiation," Proceedings 3rd International Symposium on Remote Sensing of Environment, University of Michigan, Ann Arbor, 1964.

[5] Stockhoff, E. H. and R. T. Frost, "Polarization of Light Scattered from Moist Soils," Proceedings 7th International Symposium on Remote Sensing of Environment, University of Michigan, Ann Arbor, 1971.

[6] Werner, H. D., et al., "Application of Remote Sensing Techniques to Monitoring Soil Moisture," Proceedings 7th International Symposium on Remote Sensing of Environment, University of Michigan, Ann Arbor, 1971.

[7] Luder, D. R., "Gray Tones," in Aerial Photographic Interpretation, pp. 76-101, McGraw-Hill Book Co., New York, 1959.

[8] Edgerton, A. T., "Engineering Applications of Microwave Radiometry," Proceedir 5 th International Symposium on Remole Sensing of Environment, University of Michigan, Ann Arbor, 1968.

[9] Poe, G. A, "Remote Sensing of the Near-Surface Moisture Profile of Specular Soils with Multi-Frequency Microwave Radiometry," Proceedings SPIE, vol. 27 November 1971.

[10] Wilheit, T., et al., "Mapping of Armospheric and Sea Ice Parameters with an Imaging Microwave Radiometer from the Nimbus 5 Satellite," Proceedings of the Electro-Optical Systems Conference, New York, September 1972.

[11] Lundien, J. R., "Terrain Analysis by Electromagnetic Means, Report 2, Radar Responses to Laboratory Prepared Soil Samples," U. S. Army Engineer Waterways Experiment Station Technical Report 3-693, Vicksburg, Mississippi, September 1966. 
[12] Dickey, F. M., R. K. Moore, C. King and J. Holtzman, "Moisture Dependency of Radar Backscatter from Irrigated and Non-Irrigated Fields at $400 \mathrm{MHz}$ and $13.3 \mathrm{GHz}$," submitted for publication to Geoscience Electronics, also CRES Technical Memorandum 177-33, University of Kansas Center for Research, Inc., Lawrence, Kansas, September 1972.

[13] MacDonald, H. C. and W. P. Waite, "Soil Moisture Detection with Imaging Radars," Water Resources Research, vol. 7, no. 1, February 1971.

[14] Ulaby, F. T., "4-8 GHz Microwave Active and Passive Spectrometer (MAPS)," CRES Technical Report 177-34, University of Kansas Center for Research, Inc., Lawrence, Kansos, January 1973.

[15] Moore, R. K., "Ground Echo," in Radar Handbook, M. I. Skolnik, Editor, McGraw-Hill Book Co., New York, 1970, pp. 25-12.

[16] Birkemeier, W. P. and N. D. Wallace, "Radar Tracking Accuracy Improvement by Means of Pulse-to-Pulse Frequency Modulation," IEEE Trans. Comm. and Elec., pp. 571-575, January 1963.

[17] Waite, W. P., "Broad-Spectrum Electromagnetic Backscatter," CRES Technical Report 133-17, Universily of Kansas Center for Research, Inc., Lawrence, Kansas, August 1970.

[18] Wiebe, M. L., "Laboratory Measurement of the Complex Dielectric Constant of Soils," Technical Report RSC-23, Texas A\&M University Remote Sensing Center, College Station, Texas, October 1971.

[19] Fisz, M., Probability Theory and Mathematical Statistics, John Wiley and Sons Inc., New York, pp. 491, 1963.

[20] Barrick, D E., "Rough Surfaces," in Radar Cross Section Handbook, G. T. Ruck, Editor, vol. 2, Plenum Press, New York, 1970. 